\title{
Identifikasi Potensi Wisata Di Kampung Nelayan Tradisional Desa Lamalera
}

Edel Meriqun Dai Batafor a,1, I Nyoman Sunarta a,2

1 edelbatafor@gmail.com ,²cairns54@yahoo.com

a Program Studi S1 Destinasi Pariwisata, Fakultas Pariwisata,Universitas Udayana, Jl. Dr. R. Goris, Denpasar, Bali 80232 Indonesia

\section{Abstract}

The village of Lamalera has great tourism potential to develope as a tourist attraction. However, it is important to consider some aspects in its development, such asaspect of the environment and the community, so that it will beneficial to the environment and can improve the economy of the community. The problem in this research was the potential of Lamalera, traditional fishing village. Data obtained in this study through observation, interview and documentation. The data were analyzed in qualitative descriptive by describing the potentials of Lamalera, traditional fishing village. The results showed physical and non physical potential of the village. The physical potential of Lamalera is white sandy beaches, crystal clear sea water, undersea view and other beauty of nature; while the non physical potential is in the form of custom ceremonial, traditional dances and religious.

Keywords: Identification, Potential and Tourism

\section{PENDAHULUAN}

Kepariwisataan mengamanatkan agar sumber daya alam dan modal kepariwisataan dapat dimanfaatkan secara optimal melalui kegiatan penyelengaraan kepariwisataan yang diamanatkan untuk memperluas dan meningkatkan pendapatan nasional serta memeratakan lapangan pekerjaan guna mendorong pembangunan daerah, sehingga dapat memperkenalkan daya tarik wisata yang ada. (UUD RI.No 10 Tahun 2009).

Pengertian tentang wisata ini diberikan batasan sebagai bentuk perjalanan yang dilakukan oleh seseorang maupun kelompok dengan tujuan untuk rekreasi serta mempelajari sesuatu yang unik di suatu destinasi wisata. Keseluruhan lingkup kegiatan pariwisata ini didukung oleh berbagai fasilitas serta layanan yang disediakan oleh pemerintah, pengusaha maupun masyarakat.

Kabupaten Lembata memiliki beranekaragam potensi wisata yang dapat dijadikan sebagai Daya Tarik Wisata yang layak untuk dikembangkan. Salah satu daerah yang menjadi tujuan wisatawan adalah kampung nelayan tradisional Desa Lamalera. Kampung ini terkenal dengan penangkapan ikan paus secara tradisional yang hanya mempergunakan peralatan tradisional seperti peledang atau perahu kayu tanpa mesin dan tempuling yang ujungnya terbuat dari baja yang dipergunakan untuk menikam ikan paus.

Oleh karena itu untuk menjadi suatu DTW yang siap menerima kunjungan wisatawan maka perlu mengemas berbagai potensi wisata yang ada baik itu wisata alam dan budaya yang dimiliki sehingga dapat menjadi icon wisata potensial yang akan dinikmati oleh wisatawan.

\section{TINJAUAN PUSTAKA}

Peneiitian sebelumnya dilakukan oleh Corebima (2010) yakni Studi atraksi penangkapan ikan paus di pantai Lamalera Kabupaten Lembata Provinsi Nusa Tenggara Timur, persamaan penelitian ini dengan penelitian yang dilakukan terletak pada lokasi penelitian yakni sama-sama berada di Desa Lamalera sedangkan perbedaannya adalah identifikasi potensi wisata dengan studi atraksi penengkapan ikan paus. Dalam penelitian ini juga digunakan Tinjauan Tentang Potensi Wisata.

Potensi wisata ialah segala bentuk sumber daya yang terdapat disutau daerah yang bisa saja dikembangkan menjadi atraksi wisata. Potensi wisata terbagi dalam dua macam yakni potensi wisata alamiah yang merupakan potensi yang ada pada masyarakat seperti potensi fisik dan geografis. Sedangkan potensi budaya yang dimaksud adalah potensi yang tumbuh dan berkembang di kehidupan sosial masyarakat, kesenian, adat istiadat, mata pencaharian dan lain sebagainya. (Pendit 1994).

\section{METODE PENELITIAN}

Penelitian ini berlokasi di Kampung nelayan tradisioal Desa Lamalera yang terletak sekitar 47 KM dari pusat kota Kabupaten Lembata. pemilihan lokasi didasarkan atas kondisi yang ditemukan bahwa kampung nelayan ini memiliki potensi untuk dikembangkan menjadi daya tarik wisata. 
Lokasi ini juga sering dikunjungi oleh wisatawan mancanegara maupun wisatawan nusantara.

Sumber Data dalam tulisan ini terdiri dari dua sumber data yakni Data Primer dan Data Sekunder. Data primer diperoleh melalui observasi secara langsung dan hasil wawancara dengan kepala Disbudpar Kabupaten Lembata, pelaku pariwisata dan tokoh masyarakat. Data sekunder diperoleh dari pihak-pihak yang berkompeten dan instansi terkait berupa data geografis dan demografis, literatur lain yang berkaitan dengan masalah yang dibahas.

Teknik Pengumpulan data terdiri dari beberapa teknik yakni Observasi yaitu pengamatan yang dilakukan secara langsung ke lokasi penelitian untuk mengetahui permasalahan yang akan diteliti (Subagyo 2005). Observasi dalam tulisan ini yakni melakukan pengamatan secara langsung ke lokasi penelitian yakni Desa Lamalera untuk memperoleh gambaran yang jelas berkaitan dengan potensi wisata yang ada di kampung nelayan tradisional Desa Lamalera.

Dokumen merupakan catatan peristiwa yang sudah berlalu yang berbentuk tulisan, gambar, atau karya monumental dari seseorang (Sugiyono dalam Imam Gunawan 2013). Dokumen dalam tulisan ini berupa gambar/foto mengenai potensi wisata yang ada di kampung nelayan tradisional Desa Lamalera.

Teknik analisis data dalam tulisan ini adalah analisis deskriptif kualitatif dengan meninjau dan menguraikan keteranganketerangan atau data-data yang dikumpulkan selama melakukan penelitian (Sugiyon0 2000). Analisis data ini dilakukan dengan mengumpulkan catatan deskripsi lapangan, yaitu semua informasi baik hasil observasi, dan dokumentasi.

\section{HASIL DAN PEMBAHASAN}

Desa Lamalera pada mulanya, adalah satu desa saja yang kemudian ditingkatkan menjadi dua buah desa, yaitu Desa Lamalera A dan B, dan merupakan dua buah Desa dari ke-16 buah Desa dalam wilayah Kecamatan Wulandoni di pulau Lembata, Kabupaten Lembata. Desa Lamalera berada sekitar $23^{\circ}$ bujur timur dan $8,30^{\circ}$ lintang selatan . Desa Lamalera A meliputi Lefo Lei, Lefo Lollo, Fung, dan dusun Lamamanu, sedangkan desa Lamalera B meliputi dusun Lefo Belle, Futung Lollo, dan dusun Ongaona.

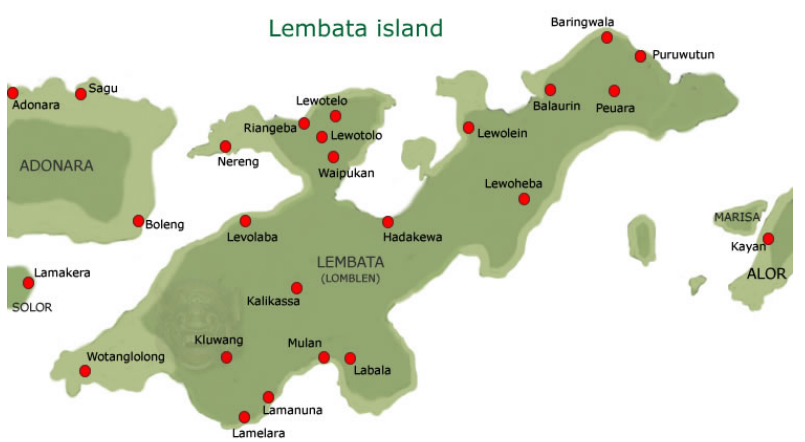

Luas wilayah desa Lamalera A dan B sekitar $1.400 \mathrm{Ha}$, dimana geografisnya terdiri dari $75 \%$ tanah berbukit yang kering dan berbatu-batu. Pesisir pantai Lamalera A terdiri dari tebing-tebing yang terjal dan berbatu wadas, sehingga tidak ada tempat-tempat khusus untuk berlabuh. Sedangkan di pesisir pantai desa Lamalera B lebih landai dan lebih ideal untuk dijadikan tempat berlabuh.

Desa Lamalera A dan B sebelah timur berbatasan dengan Desa Wulandoni, sebelah utara berbatasan dengan Desa Imulolong sebelah barat berbatasan dengan Lelata dan sebelah Selatan berbatasan dengan bentangan laut sawu.

Potensi yang dimiliki kampung nelayan Desa Lamalera memiliki berbagai potensi yang dapat dikembangkan untuk kepentingan pariwisata. untuk itu perlu dilakukan pengidentifikasiaan potensi sebagai pengembangan daya tarik wistaa dengan memperhatikan potensi dan karakteristiknya. Kampung nelayan tradisional Desa Lamalera memiliki potensi wisata yang layak untuk dikembangkan. potensi fisik yang dimiliki kampung nelayan Desa Lamalera adalah segala sesuatu yang dapat dilihat secara langsung. Potensi yang dimaksud adalah:

1. Pantai Lamalera yang berpasir putih dengan pecahan-pecahan karang yang halus sehingga sangat memungkinkan bagi wisatawan untuk berjemur, berjalan-jalan dan melakukan aktivitas lain di sekitar Pantai Lamalera. 


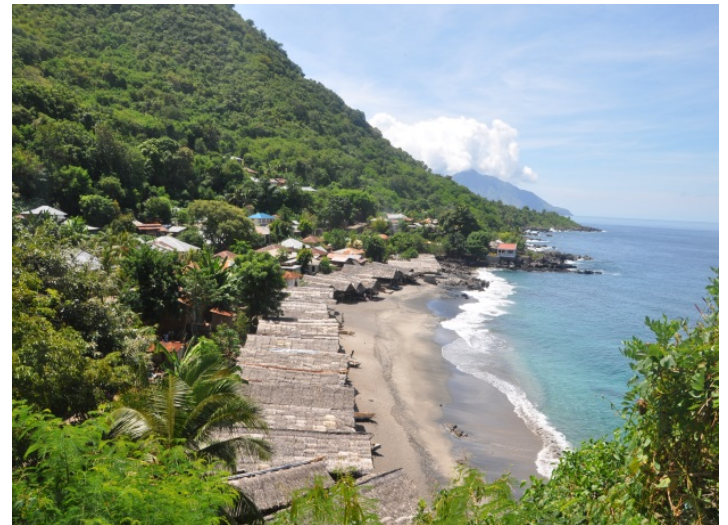

2. Air laut yang sangat jernih sangat mendukung aktivitas wisata seperti diving dan Snorkelling.

3. Deburan ombak yang cukup besar sangat cocok untuk kegiatan berselancar.

4. Pada saat sore hari wisatawan dapat menyaksikan dan menikmati tengelamnya matahari (sunset).

5. Perahu nelayan atau dalam bahasa lamalera biasa disebut peledang terletak disekitar bibir pantai dimana perahuperahu tersebut disimpan dan ditata pada rumahnya masing-masing yang berbahan tradisional.

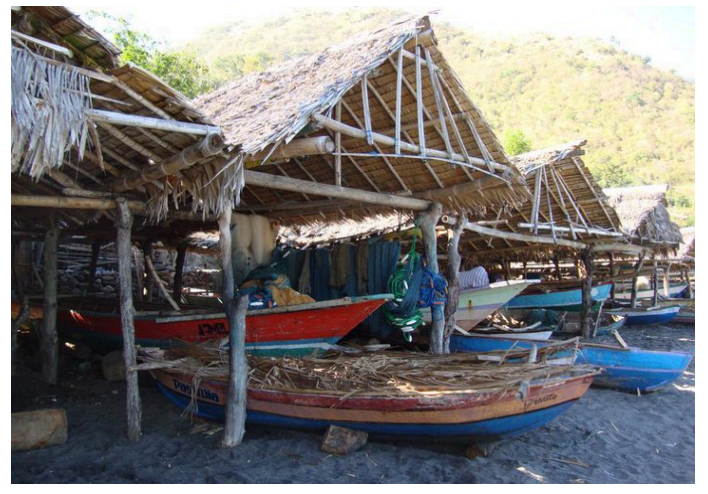

6. Fasilitas yang tersedia

a. Akomodasi, Terdapat beberapa home stay yang bisa digunakan oleh wisatawan yakni Felmina home stay, Maria Kelala home stay, yos pandai bataona home stay, dan guru ben Ebang home stay

b. Rumah makan, wisatawan dapat menikmati hidangan dan masakan pada masing-masing home stay yang ada di Lamalera.

c. Kamar Mandi/WC, Terdapat kamar mandi/wc umum di Desa Lamalera

d. Gazebo, Terdapat beberapa tempat peristirahatan di sekitar pantai Lamalera yang sangat menarik karena letaknya sangat strategis.

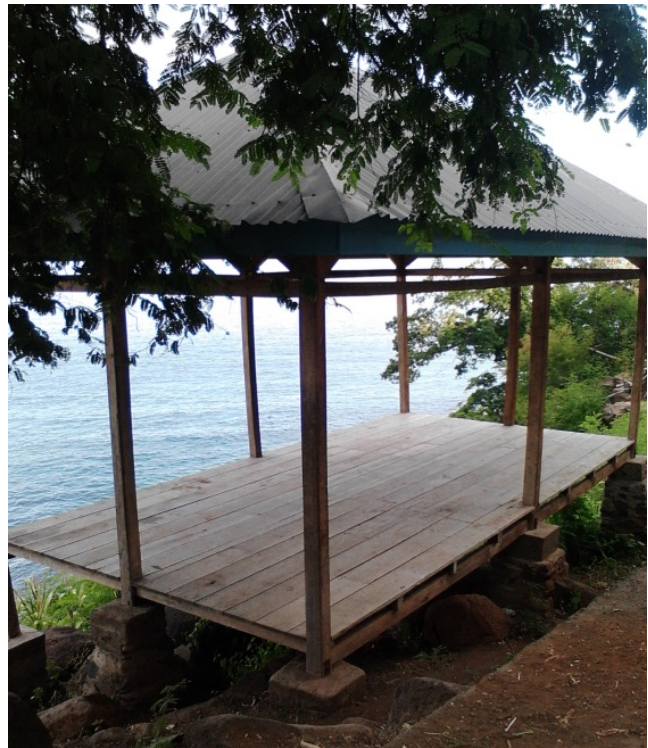

Potensi Non Fisik yang dimiliki kampung nelayan tradisonla Desa Lamalera yang mempunyai nilai dan daya tarik sendiri baik itu kesenian tradisional maupun kehidupan masyarakat setempat yang masih sangat kental seperti kesenian, adat istiadat, upacara keagamaan. Potensi non fisik yang dimaksud adalah sebgai berikut:

\section{Kesenian}

Terdapat beberapa tarian daerah antara lain buhu lelu dimana tarian ini mengkisahkan seorang perempuan yang melakukan kegiatan pembuatan sarung atau tenun ikat mulai dari proses pemilihan dan pembuatan benang sampai proses menenun.

Tenunan untuk kaum laki-laki tidak menggunakan motif, sedangkan untuk kaum perempuan bisa saja menggunakan motif peledang berpasangan dengan ikan paus dan ada juga motif pari.

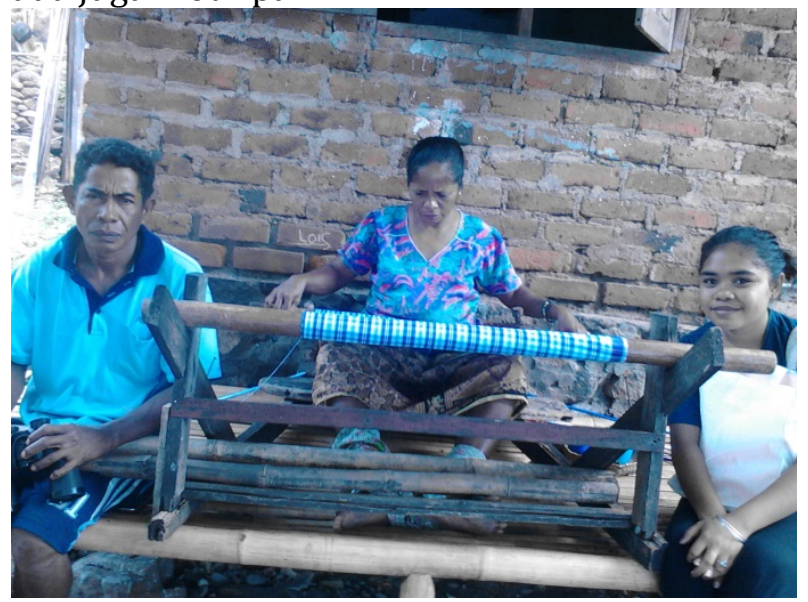


Tenun ikat di Desa Lamalera biasanya dikenal dengan tiga macam yakni sarung yang digunakan sehari-hari, sarung yang digunakan untuk keperluan adat, dan juga braggi. Sarung sehari-hari adalah kain tenun dengan mempunyai motif yang umum. Biasanya, tenunan ini mempunyai motif garis-garis panjang. Sarung yang digunakan sehari-hari terbagi atas dua jenis yakni kfatek dan noffi.

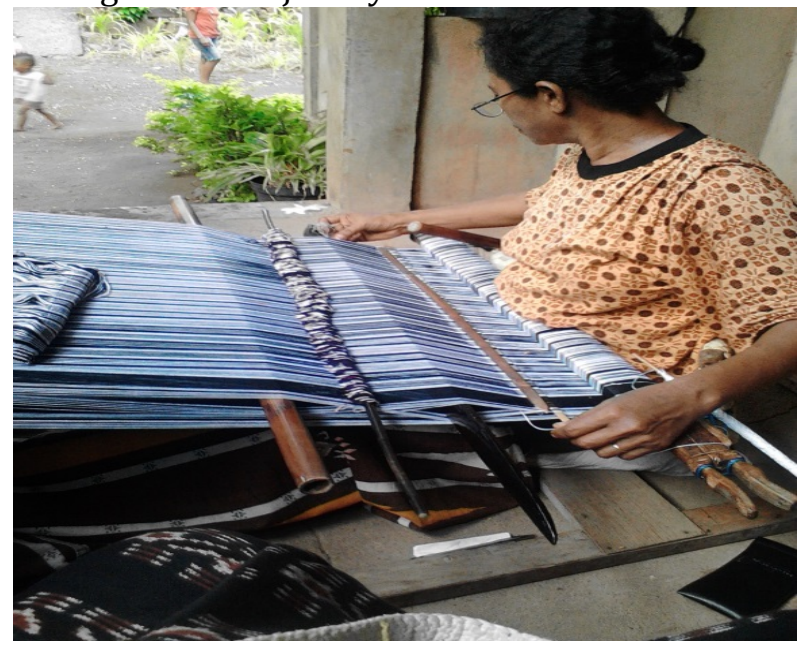

Kfatek merupakan tenunan untuk para wanita, sedangkan tenunan laki-laki biasa disebut noffi. Selain itu juga wanita Lamalera juga menenun sarung adat. Yang masuk dalam kategori kain adat yakni semua kain tenunan yang digunakan untuk keperluan urusan adat. Sarung adat dikenal dengan nama kfatek nei rue (dua lirang) yakni ditenun dua bagian setelah itu baru dijahit sambung menjadi satu dan kfatek nai tello (tiga lirang) Sarung adat tersebut mendapatkan perlakuan khusus. Selain itu juga ada beberapa tarian yakni :

Tarian Baleo, dimana tarian ini mengkisahkan perjuangan para lelaki dalam mencari nafkah (berburuh ikan paus).

Tarian ola morip yakni pengabungan antara tarian Edang dan tarian Baleo dimana dalam tarian ini menceritrakan antara pekerjaan kaum perempuan dan laki-laki di Desa Lamalera.

2. Upacara atau ritual adat

a. Tobu Nama fatta merupakan upacara dimana pada tanggal 29 April tua-tua kampung menghimpun rakyat dari ke dua kampung (Teti Lefo dan Lali Fate) desa Lamalera A dan B, bersama tuan-tuan tanah (Leffo tanah Alep) untuk membicarakan masalah Ola Nue (menyangkut masalah mata pencaharian di laut). Semua rakyat dari ke dua kampung yang telah dikumpulkan itu akan duduk saling berhadapan di depan kepela santu petrus dan paulus dan saling menyuguhi sirih pinang dan salah seorang Ata Mole(orang pandai) atau tua kampung dari satu pihak, mulai angkat bicara tentang masalah Ola Nua, agar tahun berjalan ke dua kampung itu akan menghadapi hal-hal yang baik saja di laut.

Begitupun banyak hasil yang akan diperoleh untuk kepentingan bersama. Dan rakyat disekeliling gunung, termasuk semua janda dan yatim piatu. Setelah selesai pembicaraan masalah Ola Nua mereka akan menentukan dua buah perahu yang bakal turun ke laut seusai misa pembukaan musim Lefa di pantai pada tanggal 01 bulan Mei tahun itu.

b. Legerek merupakan upacara yang dilakukan oleh tuan tanah Langowujo yang bertempat di kampung lama pada sebuah batu yang bentuknya menyerupai ikan paus atau biasa disebut dengan (fato koteklema) upacara tersebut dilakukan dengan memohon doa restu dan berkat leluhur agar pada musim Lefa tersebut masyarakat Desa Lamalera dapat memperoleh hasil penangkapan yang baik guna memberi makan para janda dan juga yatim piatu.upacara tersebut dapat dilihat pada gambar dibawah ini.

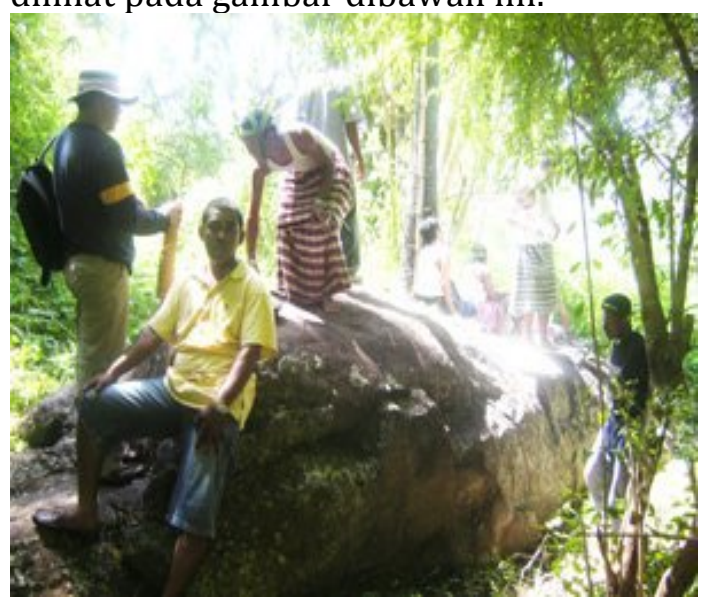

c. Misa Arwah merupakan upacara yang dilakukan untuk mendoakan arwah kaum lelaki yang meninggal di laut saat sedang mencari nafkah.

d. Misa Leva merupakan upacara rutin di Desa Lamalera yakni ritual pembukaan musim penangkapan yang dilaksanakan setiap tanggal 01 Mei di tahun tersebut. Upacara ini dilaksanakan di pesisir pantai Desa Lamalera B di depan kepela santu petrus dan paulus Lamalera dengan tujuan memohon berkat dari TYME agar segala proses penangkapan ikan paus 
yang berlangsung dari bulan meiseptember dapat berjalan dengan lancar.

Masyarakat nelayan Lamalera percaya sebelum memulai suatu kegiatan atau pekerjaan yang besar dan membutuhkan waktu yang lama. Maka selalu saja di awali dengan suatu upacara baik itu upacara adat dan upacara keagamaan yang religius. Yang dapat dilihat pada gambar dibawah ini.

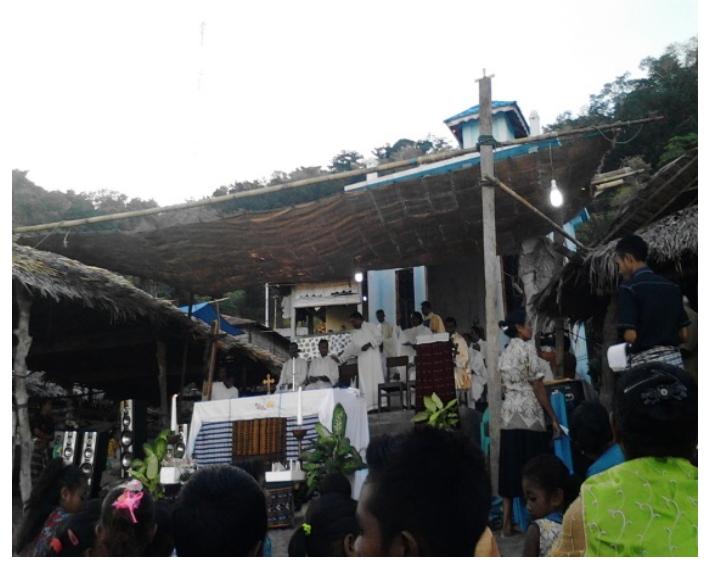

Disinilah doa-doa dipanjatkan dan menuangkan segala harapannya. Kiranya musim leva tahun ini boleh memberi makan secukupnya bagi orang-orang sekampung, anak-anak yatim piatu dan para janda serta orang kampung lainnya disekeliling gunung.

\section{SIMPULAN DAN SARAN}

1. Simpulan

Potensi yang terdapat di Desa Lamalera adalah :

a. Potensi fisik, berupa pantai dengan pasir putih, ombak yang cukup besar, air laut yang jernih, keindahan bawah laut yang mengagumkan, keindahan alam dan terdapat perahu-perahu nelayan disekitar bibir pantai. Aksesibilitas dan fasilitas yang tersedia juga mendukung untuk dilakukan pengembangan potensipotensi wisata tersebut sebagai daya tarik wisata.

b. Potensi non fisik, berupa kesenian yakni tarian buhu lelu, tarian baleo, tarian ola morip serta adanya beberapa ritual atau upacara adat yakni Tobu Neme Vata, upacara le gerek, Misa Leva dan Leva Nuang.
Setiap tahun semua ritual ini wajib dilakukan di Desa Lamalera.

\section{Saran}

Pariwisata merupakan hal yang baru bagi masyarakat, oleh karena itu kepada pemerintah, pengusaha dan pelakupelaku pariwisata harus bekerja sama dalam mendukung pengembangan potensi wisata yang ada di Desa Lamalera dan masyarakat harus dilibatkan secara langsung dalam pengembangan maupun pembangunan sarana dan prasarana dalam mendukung kegiatan pariwisata di Desa Lamalera.

Berdasarkan manfaat tulisan ini, peneliti akan menjabarkan beberapa saran untuk pihak pemerintah daerah serta masyarakat lokal dalam melihat perkembangan pariwisata dimasa yang akan datang.

a. Saran bagi Pemerintah yakni Disbudpar Kabupaten Lembata, untuk lebih peduli dengan pariwisata di Desa Lamalera. Hal utama yang harus diperhatikan adalah transportasi dan informasi yang dibutuhkan wisatawan maupun masyarakat lokal.

b. Saran bagi masyarakat lokal yang berperan dalam pengembangan pariwisata dalam hal ini pelaku pariwisata dan pemilik home stay, agar menjaga keletarian budaya yang dimiliki.

Berdasarkan penelitian yang dilakukan di Desa Lamalera pada bulan mei 2015, masih ditemukan beberapa kekurangan terkait dengan sarana prasarana dan transportasi. Diharapkkan dengan berkembangnya pariwisata Desa Lamalera saat ini, transportasinya harus lebih diperhatikan.

\section{Daftar Pustaka:}

Corebima Philipus Oktovianus SD ,2010.Studi atraksi penangkapan Ikan Paus di Pantai Lamalera Kabupaten Lembata Provinsi Nusa Tenggara Timur : Skripsi Fakultas Pariwsata Universitas Udayana.

Gunawan, Imam. 2013. Metode Penelitian Kualitatif Teori dan Praktik. Jakarta:Bumi Aksara.

Pendit, Nyoman S. 1999. Wisata Konvensi, Potensi Gede Bisnis Besar. Jakarta:PT. Gramedia Pustaka. 
Vol. 5 No 1, 2017

Sugiyono. 2000.Metode Penelitian. Bandung: CV Alvabeta.

Sugiyono Dr .2014 Metode Penelitian Kombinasi (Mixed Methods). Bandung: Alfabeta.

Suwena I Ketut dan Widyatmaja Ngr I Gst.2010, Pengetahuan Dasar Ilmu Pariwisata. Denpasar: Udayana University Press.

Undang-undang Republik Indonesia No.10 tahun 2009 Tentang Kepariwisataan. 